\title{
Decolonising Pākehā ways of being: Revealing third space Pākehā experiences.
}

\author{
Unpublished Ph.D thesis, Faculty of Education, University of Waikato. \\ Micheal Brown \\ The University of Waikato
}

This thesis asks two central questions. First, what kinds of experiences occur when Pākehā become interested and involved in te ao Māori (the Māori world)? Second, how might sharing of these experiences help other Pākehā better understand their relationship with Māori? The account is grounded in concepts of colonisation and the coloniser/colonised relation, Othering, Whiteness, hybridity and the third space, biculturalism, theories of movement between groups, and decolonisation. It particularly drew on Homi Bhabha's notions of the third space to theorise and explain the process of change that occurred for 13 Pākehā involved in te ao Māori. I argue that a transformative process of change occurred for the 13 participants because they became interested and engaged more in ongoing experiences of te ao Māori. I interpreted this process as "Pākehā decolonisation". In my analysis I found that at the individual level decolonisation helped these Pākehā bridge gaps that emerged as "differences" between te ao Māori and te ao Pākehā, which led them to develop a new and enriched understanding of themselves. Their engagement with te ao Māori produced exciting and rewarding experiences; the richness of these is revealed in the storylines. Also, their ongoing experiences moved towards effective strategies to engage in discussions with other Pākehā about te ao Māori, which were respectful to both Māori and Pākehā cultures. I interpreted this development as the "Pākehā educating Pākehā" strategy. My analysis also suggested that five key thematic elements-or what I call five "occurrences" of Pākehā decolonisation - existed within each participant's third space experiences. They were 1) all participants chose to engage in many diverse encounters with te ao Māori; 2) this led the individual to their discovery of nga wairua o te ao Māori (values of the Māori world), as well as to; 3 ) experiencing Othering experiences from Pākehā; 4) the ongoing choice to engage with te ao Māori developed into awareness and experience of sites/locations where equality between Māori and Pākehā existed; and 5) it was through confrontational experiences that these Pākehā began to learn successful Pākehā educating Pākehā strategies which they employed when engaging with other Pākehā about te ao Māori. The choice to enter into these experience(s) emerged as their "journey" into te ao Māori, a journey of enriched, insightful and meaningful experiences that helped these Pākehā develop a more 
sophisticated understanding of te ao Māori and their relationship to Māori within that world. The main contributions of this research are threefold. Firstly, when Pākehā enter into te ao Māori they encounter third space experiences that reveal new and enriched ways to experience te ao Māori. Secondly, third space experiences offer a "way forward" for Māori and Pākehā relationships that suggests an alternative to contestation and confrontation. Third, third space experiences provide a pathway toward a Pākehā educating Pākehā strategy. I argue that it is third space experiences that help Pākehā learn from their lived experiences of being Pākehā"-a phrase coined by historian Michael King $(1985,1999 b)$ - to become "fully Pākehā". 